\title{
Editorial: Sub-seasonal to Seasonal Predictability and Prediction of Monsoon Climates
}

\author{
Vincent Moron ${ }^{1,2 *}$, Andrew W. Robertson ${ }^{2}$ and Frédéric Vitart ${ }^{3}$ \\ ${ }^{1}$ Aix-Marseille University, CNRS, IRD, INRA, Coll France, CEREGE, Aix-en-Provence, France, ${ }^{2}$ IRI, Columbia University, \\ Palisades, NY, United States, ${ }^{3}$ Research Department, European Centre for Medium-Range Weather Forecasts, Reading, \\ United Kingdom
}

Keywords: sub-seasonal to seasonal (S2S) forecasts, S2S forecast, early warning, Monsoon climate, forecast ensembles data archives

\section{Editorial on the Research Topic}

Sub-seasonal to Seasonal Predictability and Prediction of Monsoon Climates

OPEN ACCESS

Edited by:

Luis Gimeno,

University of Vigo, Spain

Reviewed by:

Lin Wang,

Institute of Atmospheric Physics

(CAS), China

Margarida L. R. Liberato,

University of Trás-os-Montes and Alto

Douro, Portugal

*Correspondence:

Vincent Moron

moron@cerege.fr

Specialty section:

This article was submitted to

Atmospheric Science,

a section of the journal

Frontiers in Environmental Science

Received: 05 June 2018

Accepted: 05 July 2018

Published: 22 August 2018

Citation:

Moron $V$, Robertson AW and Vitart $F$

(2018) Editorial: Sub-seasonal to

Seasonal Predictability and Prediction

of Monsoon Climates.

Front. Environ. Sci. 6:83.

doi: 10.3389/fenvs.2018.00083
There is growing interest in the scientific, operational and applications communities in developing sub-seasonal to seasonal (S2S) forecasts (2 weeks to a season) to provide early warning of high-impact events such as floods, droughts, heat and cold waves. In fact, the detailed evolution of individual weather events is not predictable beyond few days to 1 (or 2) week(s) due to the chaotic internal dynamics of atmospheric motion and the sensitivity to initial conditions (Lorenz, 1965). By contrast, the probabilistic predictability of seasonal (i.e., at least three consecutive months) time scale has been established for a long time (Shukla, 1998; Goddard et al., 2001), mostly due to the interaction between the atmosphere and the slowly varying lower boundary conditions, including surface ocean (primarily, sea surface temperature -SST- but also heat content in the mixed layer) and land surface properties (such as snow cover, moisture content of the soils, etc.). Seasonal predictions have been issued routinely based on dynamical climate models, at least since the 1997-98 strong El Niño event (Barnston et al., 2010).

The focus of this research topic, "Sub-Seasonal to Seasonal Predictability and Prediction of Monsoon Climates" is on the intermediate time scales between 1 or 2 weeks and a season (Robertson et al., 2015; Vitart et al., 2017; White et al., 2017), mostly across the monsoon zone. Monsoon climates present a vivid case for the potential of sub-seasonal to seasonal prediction. Monsoon precipitation varies profoundly on multiple time and space scales, from the immense seasonal cycle, down to intra-seasonal active and break phases, monsoon synoptic depressions, mesoscale convective clusters and large diurnal variations, as well as inter-annual changes where variations in the dates of onset and withdrawal have large impacts on agriculture and populations. The S2S time scale includes the Madden-Julian oscillation (Madden and Julian, 1972; Wheeler and Hendon, 2004) but also a range of so-called Convectively Coupled Equatorial Waves (CCEWs, Kiladis et al., 2009) able to synchronize the occurrence and or intensity of shorter atmospheric events at regional scale. However, the S2S predictability of CCEWs, outside the MJO, remains to be established. Other sources of monsoonal potential predictability at S2S time scale include the slowly evolving surface boundary conditions mentioned above. It is well established that ENSO events impact significantly the timing of onset (or the demise) of the rainy season in many tropical regions (for example Moron et al., 2009a,b for the onset of the rainy season in Indonesia and the Philippines). Land-atmosphere interactions may also provide some predictability, for example through the progressive moistening of soils in the rainy season. Monsoonal weather is often characterized by the occurrence of heavy rainfall events and long dry spells, associated with 
active and break phases of the monsoon, and by large year-toyear variations in onset and end dates with severe impacts on agricultural livelihoods. Heat waves in the pre-monsoon months are becoming more severe as a result of increasing greenhouse gases. These surface weather intraseasonal characteristics can often be interpreted synoptically in terms of large scale circulation patterns, whose frequencies are in turn modulated by the MJO (and possibly other CCEWs) and ENSO (Moron et al., 2012).

Two papers of the research topic (Vigaud et al.; Bombardi et al.) offer a global picture of the predictability across the tropical zone from multi-model ensembles (MMEs) of S2S retrospective forecasts. Vigaud et al. establish the subseasonal forecast skill over the North American (NAM), West African and Asian boreal summer monsoon regions, focusing on weekly, and especially week 3-4, averages of precipitation from forecast starts in MayAugust. As in the case of seasonal forecasts, the advantage of MME for sub-seasonal forecasts is shown to generally improve on the individual-model skill in most cases. The influence of slower phenomena is seen in the higher skill obtained during La Niña compared to El Niño and ENSO-neutral conditions, especially for the NAM region. Bombardi et al. show that precipitation skill is often high enough to identify onset and demise dates of the rainy season in many monsoon regions at sub-seasonal ( $\sim 30$ days) lead-times, especially over South America, East Asia (EA), and Northern Australia. In summary, both studies indicate the potential for skillful subseasonal predictions at regional-scale, either for weekly or 14-day averages (Vigaud et al.), and for specific intraseasonal characteristics including onset and demise of the rainy seasons (Bombardi et al.).

Zhao et al. investigate surface air temperature anomalies in EA on the 10-30-day time scale in summer. The southeastward propagation of the surface air temperatures from western Siberia is mostly related to the advection by the mean wind associated with a mid-latitude Rossby wave, consistent with the propagation in upper-tropospheric geopotential height. This mode impacts significantly the occurrence of heat waves in Eastern China.

Two other papers examine the S2S predictability for tropical regions, usually using a single model simulation. Drosdowsky and Wheeler focus on subseasonal ( $<35$ day) predictions of areaaveraged convection-from outgoing longwave radiation (OLR) over Northern Australia in the POAMA model. The root-meansquare (RMS) error of the forecast OLR anomalies, removing the model's own seasonal cycle of OLR, is smaller than the RMS error of persistence and climatological reference forecasts for leads 335 days. Olaniyan et al. using the ECMWF model emphasized the poor predictions of the African Easterly Jet, while the latitudinal position of the Inter-Tropical Discontinuity across West Africa

\section{REFERENCES}

Barnston, A. G., Li, S., Mason, S. J., DeWitt, D. G., Goddard, L., and Gong, X. (2010). Verification of the first 11 years of IRI's seasonal climate forecasts. J. Appl. Meteorol. Climatol. 49, 493-520. doi: 10.1175/2009JAMC 2325.1 is better predicted. As in seasonal forecasts, the reproducibility of the atmospheric dynamics by the model provides a better measure of rainfall prediction than the actual quantitative rainfall forecasts especially, in areas south of $10^{\circ} \mathrm{N}$.

The last two papers of the topic (Halder et al.; Mohan et al.) focus on the Indian and South Asia summer monsoon using the Climate Forecast System version 2 (CFSv2) model. Halder et al. shown that the deterministic prediction skill of near surface temperature and soil moisture is improved on monthly and seasonal time scales using realistic land initial conditions, especially in those areas where the land-atmosphere coupling is the strongest. The re-emergence of skill in temperature and precipitation toward the end of the season over northwest India in hindcasts initialized in April and June may be attributed to better simulation of the withdrawal phase of the monsoon, as well as increased land-atmosphere coupling, as suggested in Moron et al. (2017). Mohan et al. assessed the representation of extended ( $>7$ days) active and break monsoon episodes over South Asia in 30 years of output from a long coupled CFSv2 simulation. Despite systematic biases, model solutions capture many aspects of monsoon extended break and active episodes realistically. SST variations over the northern Bay of Bengal, where the climatological mixed-layer is thin, lead the in-situ precipitation anomalies by $8-10$ days during extended active and break episodes, and the precipitation anomalies over central India by 10-14 days, associated mostly with the horizontal advection of moisture.

In summary, this topic research illustrates some of the issues and challenges of S2S predictability and predictions. Major challenges include reducing model systematic errors, improving the representation and prediction of major sources of sub-seasonal predictability and their teleconnections as well as their relationships with the local to regional scales temperature and rainfall variations. Future researchs to fill the gaps between weather and seasonal climate predictions will benefit from extensive data archives of weather and climate model ensemble forecasts which have recently become available (www.s2sprediction.net). It provides a critical new resource for answering these unresolved scientific questions of S2S predictability, and developing forecast products designed for societal applications, with the potential to help build resiliency to weather and climate shocks that affect billions of people in countries across Africa, Asia and the Americas.

\section{AUTHOR CONTRIBUTIONS}

All authors listed have made a substantial, direct and intellectual contribution to the work, and approved it for publication. 
Lorenz, E. N. (1965). A study of the predictability of a 28- variable atmospheric model. Tellus A 17, 321-333. doi: 10.1111/j.2153-3490.1965.tb 01424.x

Madden, R. A., and Julian, P. R. (1972). Description of global-scale circulation cells in the tropics with a 40-50 day period. J. Atmos. Sci. 29, 1109-1123. doi: 10.1175/1520-0469(1972)029<1109:DOGSCC >2.0.CO;2

Moron, V., Lucero, A., Hilario, F., Lyon, B., Robertson, A. W., and DeWitt, D. G. (2009a). Spatio-temporal variability and predictability of summer monsoon onset over the Philippines. Clim. Dyn. 33, 1159-1177. doi: 10.1007/s00382-0080520-5

Moron, V., Robertson, A. W., and Boer, R. (2009b). Spatial coherence and seasonal predictability of monsoon onset over Indonesia. J. Clim. 22, 840-850. doi: 10.1175/2008JCLI2435.1

Moron, V., Robertson, A. W., and Ghil, M. (2012). Impact of the modulated annual cycle and intraseasonal oscillation on daily-to-interannual rainfall variability across monsoonal India. Clim. Dyn. 38, 2409-2435. doi: 10.1007/s00382-011-1253-4

Moron, V., Robertson, A. W., and Pai, S. (2017). On the spatial coherence of subseasonal Indian rainfall anomalies. Clim. Dyn. 49, 3403-3423. doi: 10.1007/s00382-017-3520-5

Robertson, A. W., Kumar, A., Peña, M., and Vitart, F. (2015). Improving and promoting subseasonal to seasonal prediction. Bull. Amer. Meteor. Soc. 96, ES49-ES53. doi: 10.1175/BAMS-D-1400139.1
Shukla, J. (1998). Predictability in the midst of chaos: a scientific basis for climate forecasting. Science 282, 728-731. doi: 10.1126/science.282.5389.728

Vitart, F., Ardilouze, C., Bonet, A., Brookshaw, A., Chen, M., Codorean, C., et al. (2017). The Subseasonal to Seasonal (S2S) prediction project database. Bull. Amer. Meteor. Soc. 98, 163-173. doi: 10.1175/BAMS-D-16-0017.1

Wheeler, M. C., and Hendon, H. H. (2004). An all-season real-time multivariate MJO index: development of an index for monitoring and prediction. Mon. Wea. Rev. 132, 1917-1932. doi: 10.1175/1520-0493(2004)132<1917:AARMMI>2.0 $\mathrm{CO} ; 2$

White, B. J., Carlsen, H., Robertson, A. W., Klein, R. J. T., Lazo, J. K., Kumar, A., et al. (2017). Potential applications of subseasonal-to-seasonal (S2S) prediction. Meteol. App. 24, 315-325. doi: 10.1002/met.1654

Conflict of Interest Statement: The authors declare that the research was conducted in the absence of any commercial or financial relationships that could be construed as a potential conflict of interest.

Copyright (c) 2018 Moron, Robertson and Vitart. This is an open-access article distributed under the terms of the Creative Commons Attribution License (CC BY). The use, distribution or reproduction in other forums is permitted, provided the original author(s) and the copyright owner(s) are credited and that the original publication in this journal is cited, in accordance with accepted academic practice. No use, distribution or reproduction is permitted which does not comply with these terms. 